\title{
Comparison of Thoracic Radiotherapy Efficacy Between Patients With and Without EGFR-mutated Lung Adenocarcinoma
}

\author{
MING-HSIEN LI ${ }^{1}$, JO-TING TSAI ${ }^{1,2}$, LAI-LEI TING ${ }^{3}$, JANG-CHUN LIN $^{1}$ and YU-CHANG LIU ${ }^{4,5}$ \\ ${ }^{1}$ Department of Radiation Oncology, Shuang Ho Hospital, Taipei Medical University, Taipei, Taiwan, R.O.C.; \\ ${ }^{2}$ Department of Radiology, School of Medicine, College of Medicine, \\ Taipei Medical University, Taipei, Taiwan, R.O.C.; \\ ${ }^{3}$ Department of Radiation Oncology, Taipei Medical University Hospital, Taipei, Taiwan, R.O.C.; \\ ${ }^{4}$ Department of Radiation Oncology, National Yang-Ming University Hospital, Yilan, Taiwan, R.O.C.; \\ ${ }^{5}$ Department of Radiological Technology, Central Taiwan University of Science and Technology, Taichung, Taiwan, R.O.C.
}

\begin{abstract}
To investigate the association between tumor response to thoracic radiotherapy and epidermal growth factor receptor (EGFR) mutation status in patients with lung adenocarcinoma, we collected 48 patients treated between January 2010 and December 2013. Of the 18 patients with EGFR mutation, 15 (83.3\%) had a single mutation, and three (16.7\%) had double mutation. Different EGFR mutation subtypes exhibited different responses to radiotherapy. The identified double EGFR mutations were associated with reduction of residual tumor burden (RTB) after radiotherapy. In univariate analysis, EGFR mutations in exon 18, 20, and 21 and double EGFR mutation were significant factors predicting $R T B$. In multivariate analysis, exon 20 mutation was the only significant factor. Patients with EGFR mutation seemed to have longer mean overall survival (OS) compared to the group with wild-type EGFR (31.1 vs. 26.6 months, $p=0.49)$. The median and mean $O S$ in patients with double EGFR mutation vs. wild-type EGFR were 20.1 vs. 16.9 months and 28.9 vs. 26.6 months, respectively. Further studies with larger sample size are warranted to clarify the association of EGFR mutation status with the lung tumor response after radiotherapy.
\end{abstract}

Lung cancer has been the most frequent cancer in the world

This article is freely accessible online.

Correspondence to: Yu-Chang Liu, MD, Department of Radiation Oncology, National Yang-Ming University Hospital, No.169, Siaoshe Rd., Yilan City, Yilan County 26058, Taiwan, R.O.C. Tel: +886 39325192 ext. 73181, e-mail: kevinyc.liu@gmail.com

Key Words: Lung adenocarcinoma, epidermal growth factor receptor mutation, radiotherapy, double EGFR mutation. for several decades and is the major cause of cancer-related deaths worldwide (1). Non-small cell lung cancer (NSCLC) accounts for $80 \%$ of all lung cancer cases, and approximately $40 \%$ of NSCLCs are adenocarcinomas. Lung radiotherapy is the standard treatment for patients with unresectable, locally advanced NSCLC and is an effective approach to relieve the symptoms in patients with end-stage NSCLC.

In East Asians, epidermal growth factor receptor (EGFR) mutations were detected in $51.4 \%$ of all lung adenocarcinomas (2). The mutation frequency was $61.1 \%$ in females and $44.0 \%$ in males and was highest among the never-smokers $(60.7 \%)$. The occurrence of EGFR mutation is a strong predictor in patients with advanced adenocarcinoma who are treated with the EGFR-tyrosine kinase inhibitor (TKI). However, EGFR-mutated adenocarcinomas are heterogeneous in their response to EGFR-TKI (3). Patients with mutation in exons 18,19 , or 21 are sensitive to EGFRTKI therapy, whereas mutations in exon 20 are associated with EGFR-TKI resistance. Furthermore, the patients harboring $E G F R$ mutations display a trend toward a better response to chemotherapy $(4,5)$. The $E G F R$ mutation status may influence the way in which a lung cancer behaves and how well the tumors might respond to a specific treatment. Indeed, a previous study revealed a higher intracranial treatment response rate to radiotherapy in patients with EGFR-mutant NSCLC with brain metastasis (6). Another study demonstrated a better overall response rate and fewer locoregional relapses in EGFR-mutant patients (7).

Therefore, the aim of this study was to investigate the association between tumor response after thoracic radiotherapy and EGFR mutation status in patients with lung adenocarcinoma. In addition, we explored the influence of the EGFR mutation subtypes on radiosensitivity and overall survival (OS). 


\section{Materials and Methods}

Patients and EGFR mutation status determination. Between January 2010 and December 2013, 95 patients with lung adenocarcinoma from three university hospitals (namely Shuang Ho Hospital of Taipei Medical University, Taipei Municipal Wanfang Hospital, and Taipei Medical University Hospital) were referred to receive lung tumor radiotherapy. Under the Institutional Review Board-approved protocol (TMU-JIRB No.: 201411055), we reviewed the medical records of all these patients. The lung adenocarcinoma diagnosis was based on histological examination and immunohistochemical staining of biopsied tumor specimens. Patients without complete course of radiotherapy, EGFR mutation testing, or documentation of follow-up imaging at 4 months after completion of radiotherapy were excluded from the study and consequently 48 patients were enrolled in the analysis. The EGFR mutational status of all patients was analyzed using the same tumor specimen, fixed by formalin and embedded in paraffin, as that obtained at the time of initial diagnosis. Positive EGFR mutations were validated by using the QIAamp DNA Mini Kit (QIAGEN, Germantown, MD, USA) or the Cobas EGFR Mutation Test (Roche Molecular Diagnostics, Pleasanton, CA, USA).

Radiotherapy technique and prescribed dose. All patients received radiotherapy for a single lung tumor to control disease progression or relieve tumor-related symptoms. Computed tomography (CT)-based simulation and three-dimensional conformal radiotherapy planning were used. For the reason that both conventional (daily dose 1.8-2 Gy) and hypofractionation (daily dose 3-10 Gy) schemes were adopted, the radiation dose prescribed to the tumor was converted into biologically effective dose using $\alpha / \beta=10\left(\mathrm{BED}_{10}\right)$ according to the linear quadratic modeling method (8).

Review of charts. The medical record of each patient was reviewed thoroughly and the potential confounding variables affecting tumor response to radiotherapy and patient's survival were recorded for analysis. These variables relate to immunohistochemical status of tumor tissue [thyroid transcription factor 1 (TTF1), cytokeratin 7 (CK7), cytokeratin 20 (CK20), and EGFR mutations], tumor serum markers [carcinoembryonic antigen (CEA), cancer antigen 19.9 (CA19.9), and cancer antigen 125 (CA125)], and tumor irradiated dose $\left(\mathrm{BED}_{10}\right)$. The other clinical factors selected for analysis were gender, age, cigarette smoking status, clinical staging [according to the seventh edition of the cancer staging system of the American Joint Committee on Cancer (AJCC) (9)], combined systemic treatment modalities, and the sum of the longest tumor diameter (SLD) obtained by pre-radiotherapy CT scan. In accordance with the Response Evaluation Criteria In Solid Tumors (RECIST) version 1.1 (10), we measured the longest diameters of tumors, from which the SLD was calculated, by CT scans using $5 \mathrm{~mm}$ slice thickness for the 48 included patients.

Evaluation of tumor response and patient survival. The tumor response for each patient was assessed as the residual tumor burden (RTB), which was calculated based on the ratio of SLD on CT scans obtained within the preceding 2 months before beginning of radiotherapy to that obtained within the 4 months following completion of radiotherapy. The secondary endpoint was the duration of survival after the initiation of radiotherapy.
Statistical analysis. The statistical evaluation was performed using IBM SPSS statistics software version 22 (IBM Corp., Armonk, NY, USA). We analyzed the differences of the selected variables between patients with 1 ung adenocarcinoma with $E G F R$ mutations and those with wild-type $E G F R$ using the Pearson chi-square test or Fisher exact test for binary data and Student's $t$-test for cardinal data. To identify the factors affecting RTB after radiotherapy, univariate and multivariate analyses were performed using the linear regression model. The OS was estimated by the Kaplan-Meier method and the log-rank test was used to compare survival according to the EGFR mutational status. The Cox proportional hazards model was applied to investigate the association between OS and the tested factors. $p$-Value less than 0.05 was considered statistically significant.

\section{Results}

Patient characteristics. The patients' baseline characteristics are shown in Table I. The study population consisted of 32 men and 16 women. The median ages were both 65 years (range=29-93 years) in patients with mutated or wild-type $E G F R$. Female patients had a higher proportion harboring EGFR mutation, which did not reach statistical significance (38.9\% vs. $30 \% ; p=0.75)$, and the patients with mutated EGFR had a statistically lower ratio of cigarette smoking habit. Most patients had locoregionally advanced or metastatic disease (the clinical AJCC stage was I in three patients, II in one, III in 19, and IV in 25). Regarding the treatment modality, 37 patients received combined chemotherapy and radiotherapy, six patients received radiotherapy with EGFR-TKIs, and five received radiotherapy alone. The total radiation dose with conventional regimen ranged from 44 to $70 \mathrm{~Gy}$ (mean=59.9 $\pm 5.2 \mathrm{~Gy}$ ), while that with hypofractionation regimen ranged from 40 to $51 \mathrm{~Gy}$ (mean=47.2 $\pm 3.7 \mathrm{~Gy}$ ). The BED10 value ranged from 52.8 to $100 \mathrm{~Gy}$ and was a mean value of $72.9 \pm 7.5 \mathrm{~Gy}$. No significant difference in age, clinical stage, and radiotherapy $\mathrm{BED}_{10}$ values were found. A higher proportion of patients with mutated EGFR had received concurrent EGFR-TKIs, while patients with wild-type $E G F R$ tended to receive concurrent chemotherapy. Among the 18 patients with EGFR mutations, $15(83.3 \%)$ harbored a single EGFR mutation, and three (16.7\%) harbored double EGFR mutations. The proportions of single $E G F R$ mutation cases according to each mutation status were as follow. Exon 19 deletion mutation was observed in seven patients, exon 20 S768I mutation in one and exon $21 \mathrm{~L} 858 \mathrm{R}$ mutation in seven. Of the three patients with double EGFR mutation, two had exon 18 G719X plus exon 20 S768I mutations, and one had exon 18 G708L plus exon 21 L858R mutations.

Tumor response. The tumor response assessed by the RECIST criteria and the RTB values are summarized in Table II. RTB value was calculated as the SLD ratio acquired on the CT scans before beginning and after the completion 
Table I. Patient characteristics.

\begin{tabular}{|c|c|c|c|}
\hline & $\begin{array}{c}\text { Mutated } \\
E G F R \\
(\mathrm{~N}=18)\end{array}$ & $\begin{array}{c}\text { Wild-type } \\
E G F R \\
(\mathrm{~N}=30)\end{array}$ & $p$-Value \\
\hline Age (years) & & & 0.14 \\
\hline Median & 65 & 65 & \\
\hline Range & $36-93$ & $29-89$ & \\
\hline Gender, n (\%) & & & 0.75 \\
\hline Male & $11(61.1)$ & $21(70)$ & \\
\hline Female & $7(38.9)$ & $9(30)$ & \\
\hline Smoking status, $\mathrm{n}(\%)$ & & & 0.02 \\
\hline Never or light smoker & $12(66.7)$ & $9(30)$ & \\
\hline Heavy smoker & $6(33.3)$ & $21(70)$ & \\
\hline Clinical stage, n (\%) & & & 0.14 \\
\hline $\mathrm{I}+\mathrm{II}$ & $3(16.7)$ & $1(3.3)$ & \\
\hline III + IV & $15(83.3)$ & $29(96.7)$ & \\
\hline RT dose (Gy) & & & 0.04 \\
\hline Median & 60 & 60 & \\
\hline Range & $40-70$ & $44-70$ & \\
\hline $\mathrm{BED}_{10}(\mathrm{~Gy})$ & & & 0.19 \\
\hline Median & 72 & 71 & \\
\hline Range & $55.2-100$ & $52.8-100$ & \\
\hline Concurrent systemic treatment, $\mathrm{n}(\%)$ & & & 0.04 \\
\hline Chemotherapy & $12(66.7)$ & $25(83.3)$ & \\
\hline EGFR-TKI & $5(27.8)$ & 0 & \\
\hline None & $1(5.5)$ & $5(16.7)$ & \\
\hline \multicolumn{4}{|l|}{$E G F R$ mutation status, $\mathrm{n}(\%)$} \\
\hline Single mutation & $15(83.3)$ & & \\
\hline Exon 18 & 0 & & \\
\hline Exon 19 (deletion) & 7 & & \\
\hline Exon 20 (S768I) & 1 & & \\
\hline Exon 21 (L858R) & 7 & & \\
\hline Double mutation & $3(16.7)$ & & \\
\hline Exon 18 G719X + exon 20 S768I & 2 & & \\
\hline Exon $18 \mathrm{G} 708 \mathrm{~L}+$ exon $21 \mathrm{~L} 858 \mathrm{R}$ & 1 & & \\
\hline
\end{tabular}

RT: Radiotherapy, BED: biological effective dose, EGFR: epidermal growth factor receptor, TKI: tyrosine kinase inhibitor.

of radiotherapy. The mean RTB in all 48 patients was $55.9 \pm 29.0 \%$. There was no obvious difference in RTB between the mutated EGFR group and the wild-type $E G F R$ group $(56.7 \%$ vs. $55.4 \%)$. Notably, the mean RTB in the group with double EGFR mutation was lower than that of the group with single EGFR mutation (19.9\% vs. 64.0\%) and wild-type $E G F R$ group (55.4\%). Objective tumor response was observed in 34 out of the 48 patients $(70.8 \%)$. Two patients had complete response and stable disease was observed in 14 patients $(29.2 \%)$. There was no disease progression observed after radiotherapy.

Factors affecting tumor response. The primary endpoint was the RTB after radiotherapy. The results of univariate and multivariate analyses of the RTB prognostic factors are listed in Table III. Using univariate analysis, we found that the
Table II. Tumor response after thoracic irradiation.

\begin{tabular}{lccc}
\hline Response & $\begin{array}{c}\text { Mutated } \\
E G F R \\
(\mathrm{~N}=18)\end{array}$ & $\begin{array}{c}\text { Wild-type } \\
E G F R \\
(\mathrm{~N}=30)\end{array}$ & $\begin{array}{c}\text { All } \\
(\mathrm{N}=48)\end{array}$ \\
\hline Objective response rate, $\mathrm{n}(\%)$ & $12(66.7)$ & $21(70)$ & $34(70.8)$ \\
Complete response & $2(11.1)$ & 0 & $2(4.2)$ \\
Partial response & $10(55.6)$ & $21(70)$ & $32(66.6)$ \\
Stable disease & $6(33.3)$ & $9(30)$ & $14(29.2)$ \\
Progressive disease & 0 & 0 & 0 \\
Mean RTB (\%) & $56.7 \pm 32.7$ & $55.4 \pm 27.2$ & $55.9 \pm 29.0$ \\
Single mutation & $64.0 \pm 30.0$ & & \\
Double mutation & $19.9 \pm 19.0$ & & \\
\hline
\end{tabular}

EGFR: Epidermal growth factor receptor, RTB: residual tumor burden.

EGFR exon 18, 20, and 21 mutations, as well as the double $E G F R$ mutation, represented significant factors, with $\beta$ coefficient values of $-38.40,-48.67,23.32$ and -35.45 , respectively. In multivariate analysis, the only variable that was significantly associated with the tumor response was EGFR exon 20 mutation obtained by stepwise variable selection with $\beta$ coefficient value of $-48.671 \quad[95 \%$ confidence interval $(\mathrm{CI})=-80.81$ to $-16.54, p=0.004]$.

Overall survival. Among the 48 patients analyzed, 22 (45.8\%) died before the end of the median follow-up period of 20 months (range $=1$ to 54 months). The estimated overall survival rate at 1,2 , and 4 years from the start of radiotherapy was $65.7 \%, 45.1 \%$, and $40.6 \%$, respectively. In univariate analysis, only the pre-radiotherapy SLD was identified as a significant prognostic factor (hazard ratio $=1.01,95 \%$ CI=1.00-1.01, $p=0.04$ ) (Table IV). The RTB after radiotherapy, radiation $\mathrm{BED}_{10}$, clinical stage, and $E G F R$ mutation status did not show a significant influence on OS. There were no relevant factors associated with OS in multivariate analysis.

The patients with mutated EGFR appeared to have a longer mean OS (Figure 1) than those with wild-type $E G F R$ (31.1 vs. 26.6 months, $p=0.49$ ). The estimated 2-year OS rates after radiotherapy among patient with mutated $E G F R$ and those the wild-type EGFR were $50.9 \%$ and $41.3 \%$, respectively. Although the tumor response was significantly better and the RTB was the least in the group with double EGFR mutation (Table II), this difference did not translate into a significant OS benefit (adjusted hazard ratio $=1.81$, $p=0.61)$. The estimated median OS and mean OS in the patients with double EGFR mutant vs. those with wild-type EGFR were 20.1 (95\% CI=11.6 to 28.6) vs. $16.9(95 \%$ $\mathrm{CI}=6.2$ to 27.6$)$ months and $28.9(95 \% \mathrm{CI}=10.4$ to 47.4$) v \mathrm{~s}$. $26.6(95 \% \mathrm{CI}=18.4$ to 37.8$)$ months, respectively. 


\section{Discussion}

This study demonstrated that there was no significant difference in lung tumor response to radiotherapy between patients with mutated EGFR and those with wild-type $E G F R$. However, we noted that EGFR mutation status may influence the tumor response, particularly in the presence of mutation at exon $18,20,21$, or double mutation. The lung tumors showed a greater radiotherapy response in patients harboring the $E G F R$ exon 18,20 , or double mutation. In contrast, the patients harboring exon 21 mutation showed a poorer lung tumor response to radiotherapy.

We found that the local tumor responsiveness was similar between mutated and wild-type EGFR groups. Yagishita et al. analyzed the $E G F R$ mutational status in patients with stage III NSCLC who were treated by chemoradiotherapy (CRT) (11). They reported that the patients with EGFR mutations showed a longer local tumor control (adjusted hazard ratio $=0.49, p=0.043$ ). However, the patients with $E G F R$ mutations showed a similar objective response rate as compared to the patients expressing wild-type EGFR (79\% vs. 76\%). On the other hand, Akamatsu et al. reported a significantly higher overall tumor response rate in the mutated EGFR group as compared to the wild-type EGFR group (76.9\% vs. $41.9 \%, p=0.02)$ (7). Furthermore, Hsiao et $a l$. reported a higher intracranial tumor response rate after radiotherapy in patients with metastatic brain disease harboring EGFR mutations ( $88 \%$ vs. 59\%, p=0.005) (6). In this study, we noted that radiotherapy efficacy differed in different subtypes of patients with EGFR mutations.

In the literature, the incidence of double EGFR mutations ranged from $2 \%$ to $18 \%$ among the patients with mutated $E G F R$ (12-15). We found that the frequency of double EGFR mutation was $16.7 \%(3 / 18)$. These patients included two cases with the G719X plus S768I mutations and one case with the G708L plus L858R mutations. It is well known that ionizing radiation-induced cell death is primarily due to double-strand DNA breaks. Cells have some mechanisms to repair DNA damage, and EGFR may play a role in these mechanisms. Dittmann et al. reported that import of EGFR into the nucleus triggered by ionizing radiation was associated with activation of DNA-dependent kinase (DNA-PK) (16). An increase in the nuclear kinase activity of DNA-PK is essential for repairing DNA strand breaks. In vitro studies have revealed that EGFRmutant NSCLC cells exhibited significant delays in DNA repair because of a lack of nuclear EGFR accumulation, which contributed to their radiosensitivity (17-19). In addition, clinical researchers have reported that patients with locally advanced lung adenocarcinomas with EGFR mutations presented a longer locoregional control after definitive CRT $(7,11)$. In this study, we found that the mean tumor RTB was not significantly different between patients with and without EGFR mutation ( $56.7 \%$ vs. $55.4 \%)$. However, the double
Table III. Univariate analyses of prognostic factors for residual tumor burden (RTB). By multivariate (stepwise) analysis, epidermal growth factor receptor (EGFR) exon 20 mutation was the only factor subsequently found to be significant [coefficient $=-48.67,95 \%$ confidence interval $(C I)=-80.81--16.54, p=0.004]$.

\begin{tabular}{lcc}
\hline & \multicolumn{2}{c}{ Univariate } \\
\cline { 2 - 3 } & Coefficient $(95 \%$ CI $)$ & $p$-Value \\
\hline Gender & $-12.54(-30.25-5.16)$ & 0.16 \\
Age & $-0.41(-1.03-0.21)$ & 0.19 \\
Clinical stage & $4.02(-26.81-34.85)$ & 0.79 \\
Smoking status & $-12.21(-29.01-4.60)$ & 0.15 \\
BED 10 & $-0.004(-0.12-0.005)$ & 0.37 \\
Pre-radiotherapy SLD & $0.03(-0.14-0.21)$ & 0.70 \\
Concurrent systemic treatment & & \\
Chemotherapy & $-4.24(-32.60-24.13)$ & 0.77 \\
EGFR-TKI & $3.25(-32.80-39.29)$ & 0.86 \\
None & & \\
CEA & $-0.03(-0.10-0.04)$ & 0.37 \\
CA19.9 & $-0.07(-0.38-0.24)$ & 0.64 \\
CA125 & $-0.04(-0.11-0.03)$ & 0.21 \\
CK7 & $9.52(-21.55-40.60)$ & 0.54 \\
CK20 & $-1.66(-36.68-33.37)$ & 0.92 \\
TTF1 & $12.84(-13.87-39.56)$ & 0.34 \\
EGFR mutation status & $1.47(-16.14-19.08)$ & 0.87 \\
EGFR mutation & & \\
Single mutation & $8.85(-8.84-26.54)$ & 0.32 \\
Double mutation* & $-35.45(-69.32--1.58)$ & 0.04 \\
EGFR exon 18 mutation* & $-38.40(-71.74--5.06)$ & 0.03 \\
EGFR exon 19 mutation & $-0.35(-24.51-23.82)$ & 0.98 \\
EGFR exon 20 mutation** & $-48.67(-80.81--16.54)$ & 0.004 \\
EGFR exon 21 mutation* & $23.32(1.51-45.13)$ & 0.04 \\
\hline & & \\
\hline & &
\end{tabular}

BED: Biological effective dose, CEA: carcinoembryonic antigen, CA19.9: cancer antigen 19.9, CA125: cancer antigen 125, CI: confidence interval, CK7: cytokeratin 7, CK20: cytokeratin 20, TTF1: thyroid transcription factor 1, SLD: sum of longest tumor diameter, TKI: tyrosine kinase inhibitor. *Variables excluded from multivariate analysis. **The only factor significant in multivariate (stepwise) analysis.

EGFR mutants clearly had the least mean RTB as compared to the wild-type EGFR group (19.9\% vs. 55.4\%). Our study demonstrated an obvious association between double $E G F R$ mutation and radiosensitivity during thoracic irradiation.

Previous studies have reported that in-frame deletion mutations in exon 19 and exon 21 L858R mutation accounted for approximately $90 \%$ of all EGFR mutations (20-24). Yamamoto et al. published a comprehensive review of the literature (25). They found the distribution of EGFR mutations was as follows: $48 \%$ in exon $19,43 \%$ in exon $21,4 \%$ in exon 20 , and $3 \%$ in exon 18. EGFR mutations have been identified as predictors of response to EGFR-TKIs in NSCLC. However, EGFR-mutated NSCLCs are heterogeneous in their response to EGFR-TKIs. Cheng et al. published a literature review on the association between the EGFR mutation type and response to EGFR-TKIs (3). Exon 19 deletions, L858R mutation in 


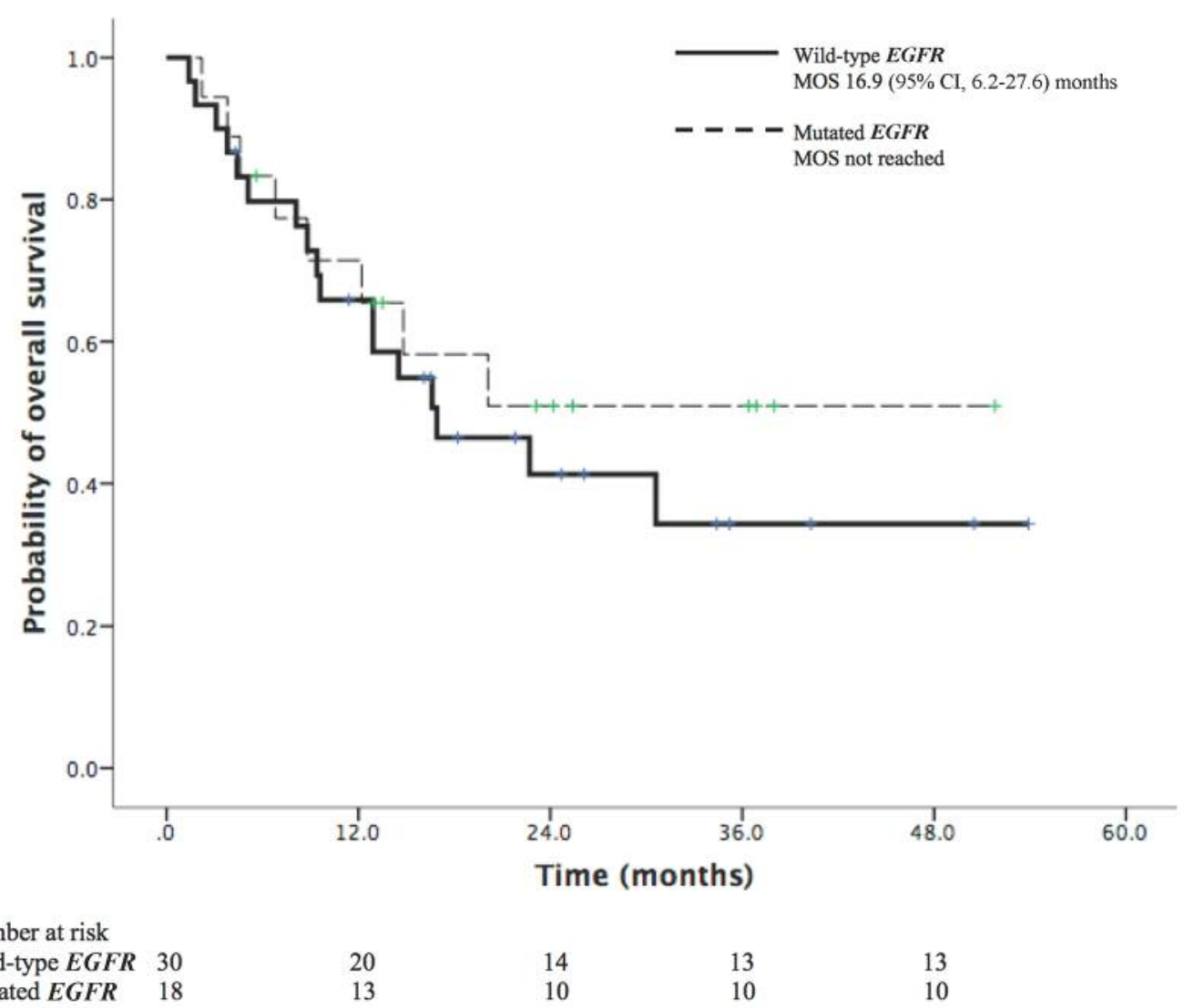

Figure 1. Overall survival curves of patients with mutated epidermal growth factor receptor (EGFR) and wild-type EGFR. MOS: Median overall survival, CI: confidence interval.

exon 21, G719X mutation in exon 18, and L861Q and L861R mutations in exon 21 were identified as biomarkers that could predict the probable benefit of EGFR-TKIs therapy for adenocarcinoma. Conversely, insertion mutations, T790M mutation in exon 20, and D761Y mutation in exon 19 were associated with resistance to the EGFR-TKIs. In this study, we found that NSCLC with mutated EGFR appeared to be heterogeneous in response to thoracic irradiation. Better radiosensitivity was observed in the patients with an exon 18 or exon 20 mutation and poorer radiosensitivity was observed in the patients with an exon 21 mutation. Using multivariate analysis, we found that only exon 20 mutation was significantly associated with the lung tumor radiotherapy response $(\beta$ coefficient $-48.67,95 \% \mathrm{CI}=-80.81$ to -16.54 , $\mathrm{p}=0.004)$. The type of exon 20 mutation identified was S768I in all cases $(n=3)$, and two of them had this mutation combined with an exon 18 mutation (G719X). Beau-Faller et al. analyzed rare EGFR exon 18 and exon 20 mutations in NSCLC (26). They found that the EGFR mutations associated with the highest EGFR-TKI sensitivity were double mutations. We also found a similar result, with patients win the rare double $E G F R$ mutations showing a better radiosensitivity as compared to those with single EGFR mutations.

Akamatsu et al. retrospectively analyzed the OS in patients with stage III NSCLC who received concurrent CRT. They reported a median OS of 30.7 months in patients expressing wild-type $E G F R$ and of 57.9 months in the patients harboring EGFR mutations, although the difference was not statistically significant (7). Yagishita et al. also reported longer median OS in patients with EGFR mutations in a retrospective analysis. They identified OS of 33.3 months in the patients expressing wild-type EGFR and of 46.9 months in the patients harboring EGFR mutations $(p=0.285)(11)$. Our survival analysis demonstrated that the OS was not significantly different between patients, regardless of their EGFR mutation status ( $p=0.49$ ). However, we noted a similar trend for a longer mean OS in the group with mutated $E G F R$ as compared to the wild-type $E G F R$ group (31.2 vs. 26.6 months, respectively). In addition, the mean OS in the patients with double EGFR mutant was longer than in those with single EGFR mutation (28.9 vs. 24.8 months, respectively). 
Table IV. Univariate and multivariate analyses of prognostic factors for overall survival.

\begin{tabular}{|c|c|c|c|c|}
\hline & \multicolumn{2}{|c|}{ Univariate } & \multicolumn{2}{|c|}{ Multivariate } \\
\hline & $\operatorname{HR}(95 \% \mathrm{CI})$ & $p$-Value & $\operatorname{HR}(95 \% \mathrm{CI})$ & $p$-Value \\
\hline Gender & $0.85(0.36-1.97)$ & 0.70 & & \\
\hline Age & $1.01(0.98-1.04)$ & 0.33 & & \\
\hline Clinical stage & $0.95(0.22-4.07)$ & 0.95 & & \\
\hline Smoking status & $0.58(0.25-1.32)$ & 0.19 & & \\
\hline $\mathrm{BED}_{10}$ & $1.00(1.0-1.0)$ & 0.23 & & \\
\hline Pre-radiotherapy SLD & $1.01(1.00-1.01)$ & 0.04 & $1.01(1.00-1.01)$ & 0.09 \\
\hline RTB & $1.00(0.99-1.01)$ & 0.99 & & \\
\hline \multicolumn{5}{|c|}{ Concurrent systematic treatment } \\
\hline Chemotherapy & $0.60(0.17-2.08)$ & 0.42 & & \\
\hline EGFR-TKI & $1.56(0.37-6.55)$ & 0.54 & & \\
\hline None & 1 & & & \\
\hline CEA & $1.00(1.00-1.01)$ & 0.07 & $1.00(1.00-1.01)$ & 0.07 \\
\hline CA19.9 & $1.00(0.99-1.01)$ & 0.82 & & \\
\hline CA125 & $1.00(0.99-1.00)$ & 0.45 & & \\
\hline CK7 & $2.99(0.93-9.65)$ & 0.07 & & \\
\hline CK20 & $0.43(0.12-1.54)$ & 0.20 & & \\
\hline TTF1 & $1.45(0.48-4.33)$ & 0.51 & & \\
\hline$E G F R$ mutation status & $1.34(0.58-3.10)$ & 0.50 & & \\
\hline \multicolumn{5}{|l|}{$E G F R$ mutation } \\
\hline Single mutation & $1.20(0.28-5.19)$ & 0.81 & $0.82(0.10-7.00)$ & 0.85 \\
\hline Double mutation & $0.86(0.17-4.30)$ & 0.86 & $1.81(0.18-17.98)$ & 0.61 \\
\hline Wild-type EGFR & 1 & & & \\
\hline$E G F R$ exon 18 mutation & $1.09(0.26-4.63)$ & 0.91 & $*$ & \\
\hline$E G F R$ exon 19 mutation & $2.34(0.55-9.94)$ & 0.25 & $4.63(0.67-31.98)$ & 0.12 \\
\hline$E G F R$ exon 20 mutation & $1.09(0.26-4.63)$ & 0.91 & $2.03(0.20-20.09)$ & 0.54 \\
\hline$E G F R$ exon 21 mutation & $0.79(0.27-2.31)$ & 0.67 & * & \\
\hline
\end{tabular}

BED: Biological effective dose, CEA: carcinoembryonic antigen, CA19.9: cancer antigen 19.9, CA125: cancer antigen 125, CI: confidence interval, CK7: cytokeratin 7, CK20: cytokeratin 20, TTF1: thyroid transcription factor 1, EGFR: epidermal growth factor receptor, RTB: residual tumor burden, SLD: sum of longest tumor diameter, TKI: tyrosine kinase inhibitor. *Degrees of freedom: 0.

The present study had several limitations. Our population was of a small sample size. Indeed, only three patients with double EGFR mutation were identified in our analysis. In addition, there was selection bias in our population. NSCLC patients with EGFR mutations may have been excluded because of the lack of post-radiotherapy follow-up CT imaging evaluation. This may affect the conclusion of the outcome comparisons after thoracic irradiation among the patients with different $E G F R$ mutation status.

In conclusion, there was no significant difference in local tumor response between groups with mutated EGFR and wild-type $E G F R$. Different subtypes of $E G F R$ mutation status exhibited different radiotherapy efficacy. Furthermore, EGFR exon 18, exon 20 and exon 21 mutations together with double mutation may represent factors that predict the lung tumor response after radiotherapy. The patients with mutated EGFR seemed to have a longer mean or median OS than those with wild-type EGFR.

Future studies with larger sample sizes may help clarify the association between the subtypes of EGFR mutation status and lung tumor response after radiotherapy in patients with lung adenocarcinoma.

\section{Conflicts of Interest}

The Authors declare they have no conflict of interest in regard to this study.

\section{References}

1 Ferlay J, Soerjomataram I, Dikshit R, Eser S, Mathers C, Rebelo M, Parkin DM, Forman D and Bray F: Cancer incidence and mortality worldwide: sources, methods and major patterns in GLOBOCAN 2012. Int J Cancer 136: E359-386, 2015.

2 Shi Y, Au JS, Thongprasert S, Srinivasan S, Tsai CM, Khoa M T, Heeroma K, Itoh Y, Cornelio G and Yang PC: A prospective, molecular epidemiology study of EGFR mutations in Asian patients with advanced non-small-cell lung cancer of adenocarcinoma histology (PIONEER). J Thorac Oncol 9: 154162, 2014.

3 Cheng L, Alexander RE, Maclennan GT, Cummings OW, Montironi R, Lopez-Beltran A, Cramer HM, Davidson DD and 
Zhang S: Molecular pathology of lung cancer: key to personalized medicine. Mod Pathol 25: 347-369, 2012.

4 Lin CC, Hsu HH, Sun CT, Shih JY, Lin ZZ, Yu CJ, Chen GG, Hsin, MK, Lam KC, Leung L, Yang $\mathrm{CH}$ and Mok $\mathrm{T}$ : Chemotherapy response in East Asian non-small cell lung cancer patients harboring wild-type or activating mutation of epidermal growth factor receptors. J Thorac Oncol 5: 1424-1429, 2010.

5 Liang W, Zhang Y, Kang S, Pan H, Shao W, Deng Q, Shi X, Wang $\mathrm{W}$ and $\mathrm{He} \mathrm{J}$ : Impact of EGFR mutation status on tumor response and progression free survival after first-line chemotherapy in patients with advanced non-small-cell lung cancer: a meta-analysis. J Thorac Dis 6: 1239-1250, 2014.

6 Hsiao SH, Lin HC, Chou YT, Lin SE, Kuo CC, Yu MC and Chung CL: Impact of epidermal growth factor receptor mutations on intracranial treatment response and survival after brain metastases in lung adenocarcinoma patients. Lung cancer 81: 455-461, 2013.

7 Akamatsu H, Kaira K, Murakami H, Serizawa M, Koh Y, Ono A, Shukuya T, Tsuya A, Nakamura Y, Kenmotsu H, Naito T, Takahashi T, Endo M, Harada H, Nakajima T and Yamamoto N: The impact of clinical outcomes according to EGFR mutation status in patients with locally advanced lung adenocarcinoma who received concurrent chemoradiotherapy. Am J Clin Oncol 37: 144-147, 2014.

8 Fowler JF, Tome WA, Fenwick JD and Mehta MP: A challenge to traditional radiation oncology. Int J Radiat Oncol Biol Phys 60: 1241-1256, 2004

9 Detterbeck FC, Boffa DJ, and Tanoue LT: The new lung cancer staging system. Chest 136: 260-271, 2009.

10 Eisenhauer EA, Therasse P, Bogaerts J, Schwartz LH, Sargent D, Ford R, Dancey J, Arbuck S, Gwyther S, Mooney M, Rubinstein L, Shankar L, Dodd L, Kaplan R, Lacombe D, and Verweij J: New response evaluation criteria in solid tumours: revised RECIST guideline (version 1.1). Eur J Cancer 45: 228-247, 2009.

11 Yagishita S, Horinouchi H, Katsui Taniyama T, Nakamichi S, Kitazono S, Mizugaki H, Kanda S, Fujiwara Y, Nokihara H, Yamamoto N, Sumi M, Shiraishi K, Kohno T, Furuta K, Tsuta K and Tamura T: Epidermal growth factor receptor mutation is associated with longer local control after definitive chemoradiotherapy in patients with stage III nonsquamous non-small-cell lung cancer. Int J Radiat Oncol Biol Phys 91: 140-148, 2015.

12 Sriuranpong V, Chantranuwat C, Huapai N, Chalermchai T, Leungtaweeboon $\mathrm{K}$, Lertsanguansinchai $\mathrm{P}$, Voravud $\mathrm{N}$ and Mutirangura A: High frequency of mutation of epidermal growth factor receptor in lung adenocarcinoma in Thailand. Cancer Lett 239: 292-297, 2006.

13 Zhang GC, Lin JY, Wang Z, Zhou Q, Xu CR, Zhu JQ, Wang K, Yang XN, Chen G, Yang JJ, Huang YJ, Liao RQ and Wu YL: Epidermal growth factor receptor double activating mutations involving both exons 19 and 21 exist in Chinese non-small cell lung cancer patients. Clin Oncol 19: 499-506, 2007.

14 Tam IY, Leung EL, Tin VP, Chua DT, Sihoe AD, Cheng LC, Chung LP and Wong MP: Double EGFR mutants containing rare EGFR mutant types show reduced in vitro response to gefitinib compared with common activating missense mutations. Mol Cancer Ther 8: 2142-2151, 2009.

15 Stone E, Allen HA, Saghaie T, Abbott A, Daniel R, Mead RS, Kohonen-Corish M, Plit M and Morgan L: High proportion of rare and compound epidermal growth factor receptor mutations in an Australian population of non-squamous non-small-cell lung cancer. Intern Med J 44: 1188-1192, 2014
16 Dittmann K, Mayer C, Fehrenbacher B, Schaller M, Raju U, Milas L, Chen DJ, Kehlbach R and Rodemann HP: Radiationinduced epidermal growth factor receptor nuclear import is linked to activation of DNA-dependent protein kinase. J Biol Chem 280: 31182-31189, 2005.

17 Das AK, Sato M, Story MD, Peyton M, Graves R, Redpath S, Girard L, Gazdar AF, Shay JW, Minna, JD and Nirodi CS: Nonsmall-cell lung cancers with kinase domain mutations in the epidermal growth factor receptor are sensitive to ionizing radiation. Cancer Res 66: 9601-9608, 2006.

18 Das AK, Chen BP, Story MD, Sato M, Minna JD, Chen DJ and Nirodi CS: Somatic mutations in the tyrosine kinase domain of epidermal growth factor receptor $(E G F R)$ abrogate EGFRmediated radioprotection in non-small cell lung carcinoma. Cancer Res 67: 5267-5274, 2007.

19 Liccardi G, Hartley JA and Hochhauser D: EGFR nuclear translocation modulates DNA repair following cisplatin and ionizing radiation treatment. Cancer Res 71: 1103-1114, 2011.

20 Kosaka T, Yatabe Y, Endoh H, Kuwano H, Takahashi T and Mitsudomi T: Mutations of the epidermal growth factor receptor gene in lung cancer: biological and clinical implications. Cancer Res 64: 8919-8923, 2004.

21 Lynch TJ, Bell DW, Sordella R, Gurubhagavatula S, Okimoto RA, Brannigan BW, Harris PL, Haserlat SM, Supko JG, Haluska FG, Louis DN, Christiani DC, Settleman J and Haber DA: Activating mutations in the epidermal growth factor receptor underlying responsiveness of non-small-cell lung cancer to gefitinib. N Engl J Med 350: 2129-2139, 2004.

22 Paez JG, Janne PA, Lee JC, Tracy S, Greulich H, Gabriel S, Herman P, Kaye FJ, Lindeman N, Boggon TJ, Naoki K, Sasaki H, Fujii Y, Eck MJ, Sellers WR, Johnson BE and Meyerson M: $E G F R$ mutations in lung cancer: correlation with clinical response to gefitinib therapy. Science 304: 1497-1500, 2004.

23 Pao W, Miller V, Zakowski M, Doherty J, Politi K, Sarkaria I, Singh B, Heelan R, Rusch V, Fulton L, Mardis E, Kupfer D, Wilson R, Kris M and Varmus H: EGF receptor gene mutations are common in lung cancers from "never smokers" and are associated with sensitivity of tumors to gefitinib and erlotinib. Proc Natl Acad Sci USA 101: 13306-13311, 2004.

24 Shigematsu H, Lin L, Takahashi T, Nomura M, Suzuki M, Wistuba II, Fong KM, Lee H, Toyooka S, Shimizu N, Fujisawa T, Feng Z, Roth JA, Herz J, Minna JD and Gazdar AF: Clinical and biological features associated with epidermal growth factor receptor gene mutations in lung cancers. J Natl Cancer Inst 97: 339-346, 2005.

25 Yamamoto $\mathrm{H}$, Toyooka $\mathrm{S}$ and Mitsudomi T: Impact of EGFR mutation analysis in non-small cell lung cancer. Lung Cancer 63: 315-321, 2009.

26 Beau-Faller M, Prim N, Ruppert AM, Nanni-Metellus I, Lacave R, Lacroix L, Escande F, Lizard S, Pretet JL, Rouquette I, de Cremoux P, Solassol J, de Fraipont F, Bieche I, Cayre A, Favre-Guillevin E, Tomasini P, Wislez M, Besse B, Legrain M, Voegeli AC, Baudrin L, Morin F, Zalcman G, Quoix E, Blons H and Cadranel J: Rare EGFR exon 18 and exon 20 mutations in non-small-cell lung cancer on 10117 patients: a multicentre observational study by the French ERMETIC-IFCT network. Ann Oncol 25: 126-131, 2014.

Received October 12, 2017

Revised October 29, 2017

Accepted November 1, 2017 